\title{
Usabilidad de las páginas de inicio de los diarios digitales españoles
}

\author{
Juan Carlos García Gómez \\ Grupo de Tecnologías de la Información \\ Universidad de Murcia (España)
}

\subsection{Resumen}

Se realiza un estudio de usabilidad de las páginas de inicio de los principales diarios españoles de información general en línea a partir de una adaptación de las propuestas de usabilidad de Nielsen. Se comienza con una breve revisión de los aspectos básicos de la usabilidad de sitios web. Los resultados muestran que, en este campo, los diarios en línea españoles, sin hacer grandes esfuerzos, tienen unos niveles aceptables; y que, paradójicamente, no son los diarios de mayor difusión los más usables, sino aquellos vinculados a grupos empresariales de tamaño intermedio.

Palabras Clave: Usabilidad. Ergonomía cognitiva. Interfaz de usuario. Internet. Diseño web. Evaluación. Diarios en línea. Diarios digitales. Portales de Internet.

\subsection{Abstract}

After a brief introduction to the basic characteristics of web site usability, a usability study of the the main online general information newspapers homepages is presented. This study was based on an adaptation of the web site usability issues proposed by Nielsen. Results show that, in this field, online Spanish newspapers have, without much effort, acceptable levels of usability. Amazingly, the most usable newspapers are not the more popular ones, but those of medium size editorial groups.

Keywords: Usability. Cognitive ergonomy. User interface. Internet. Web design. Evaluation. Online journals. Digital journals. Internet portals.

\section{Introducción: La página de inicio de los diarios en línea}

La página de inicio de un sitio web es la página más importante de éste y, normalmente, recibe muchísimas más visitas que el resto. Según la Oficina de 


\section{Juan Carlos García Gómez}

Justificación de la Difusión (2003), los lectores de diarios digitales de información general españoles leen unas siete páginas por visita. Si consideramos que la gran mayoría de ellos acceden directamente a la página principal, observamos que al menos el $15 \%$ de lo que ve el usuario en un periódico digital es la página de inicio. Además, la navegación por el resto de páginas suele tener su origen en la propia página inicial, en la que se encuentran los enlaces principales o destacados. En los diarios en línea esta página cumple la doble función de servir de guía para la navegación, por un lado, y de muestrario de los contenidos, por otro.

Es tendencia generalizada el comparar la página de inicio de una web con un escaparate. En el mundo real, éste trata de seducir al viandante para que entre precisamente en esa tienda y no en otra de las muchas que hay en la misma acera. Por lo tanto, la función básica del escaparate es la de atraer, llamar a gritos al peatón, convertirse en un reclamo. Otra de las comparaciones que se tiende a efectuar es con una portada de periódico o revista. Esta portada (sobre todo la de la revista) compite en el quiosco con el resto de publicaciones para atraer la atención del lector. La profusión de colores y grandes tipografías sirve para destacar unas informaciones sobre otras, pero también, a veces de forma primordial, para obrar como atractivo visual, y hacerle resaltar sobre el resto de publicaciones. Sin embargo, es erróneo aplicar a una página de inicio tanto la metáfora de la portada como la del escaparate, ya que el hecho de estar frente a una página de inicio no es comparable con encontrarse en un quiosco decidiendo qué comprar (Nielsen, 2002, p.7), como tampoco lo es la confrontación con un escaparate que persigue hacer entrar en un comercio.

En el caso de una página de inicio, el símil adecuado es, en realidad, una situación en la que el usuario ya tendría en la mano la publicación (en la metáfora del quiosco), o en la que ya habría entrado al establecimiento (en la metáfora del escaparate); pues el instante crítico de llamar la atención ya se superó con éxito previamente, y en ese momento sólo faltaría que el usuario decidiera comprar o no la publicación que tiene en la mano, en un caso, o adquirir algo o no en la tienda en la que acaba de entrar, en el otro.

Siguiendo con estas metáforas, para un sitio web, el lugar comparable con el quiosco o el escaparate sería aquellos lugares que le dan acceso a un usuario, tales como portales especializados que contienen un enlace a esa web o páginas personales, pero, ante todo, estamos refiriéndonos a los buscadores de Internet más importantes. De ellos, por el momento, Google se muestra claramente superior al resto (Martínez Méndez, 2002), tanto en cuanto a popularidad como en cuanto a la calidad de sus resultados. Así, el modo de ser visible en Internet, no pasa tanto por tener un diseño espectacular en la página de inicio, como en describirla correctamente, usando expresiones que expliquen apropiadamente lo que el visitante va a encontrar en el sitio web. Por tanto, si la web se ha registrado

Scire. $10: 2$ (jul.-dic. 2004) 123-136. 
en los principales buscadores, y los términos que contienen las metaetiquetas o la página de inicio son similares a los que el usuario teclea en un buscador, hay mucha probabilidad de que esa página aparezca entre los primeros lugares de los resultados de la consulta. Eso, y no el diseño estéticamente llamativo, es lo que hace visible a una página en Internet.

Por otro lado, las características de las páginas de inicio de los diarios en línea han venido marcadas desde el primer momento por la herencia de la portada de la prensa escrita. La mayoría de diarios en línea tienen su origen en la adaptación a la red de un diario impreso. Ello les ha hecho adquirir algunos de los usos característicos de los diarios impresos, tales como la utilización de columnas para distribuir la información. Sin embargo, resulta complejo e inadecuado tratar de trasladar el contenido y diseño de la portada de un diario impreso al entorno digital, sin más transformaciones que las propias del paso del soporte impreso al lenguaje HTML, característico del web. Las razones pasan por cuestiones de espacio, pues una sola pantalla estándar puede albergar menos cantidad de contenido que una portada impresa; o de adaptación al medio, debido a las implicaciones inherentes al uso del hipertexto como sistema de acceso a los contenidos; de la ausencia de limitación espacial para los textos, etc. Con el tiempo, las portadas de los diarios en línea, por regla general, han ido diferenciándose de sus ascendientes impresos, incorporando contenidos específicos para la versión en línea, tales como el acceso a servicios de valor añadido.

Los diarios en línea, dada la homogeneidad del tipo de producto que ofertan -información de actualidad - , son especialmente adecuados para ser estudiados desde el punto de vista de la usabilidad. Hacer un estudio de su eficiencia de uso resulta interesante, dado el paulatino incremento de contenidos y servicios que se han ido incorporando recientemente. Si a ello unimos el hecho de que muchos de estos sitios han pasado a cobrar por sus servicios en los últimos tiempos, un estudio de la calidad de uso de los mismos se hace más importante, si cabe, dadas las implicaciones económicas que de ello se derivan para sus grupos empresariales.

No obstante, pese a la importancia que tienen las cuestiones relacionadas con la usabilidad de los diarios en línea, en general, y de su página de inicio, en particular, no abundan los estudios al respecto, aunque cabe destacar el realizado por Donaghy (2002) sobre diarios en línea estadounidenses y, en el caso español, los de Sánchez (2002) y Arbildi y Serrano (2002) en relación el rediseño de $E l$ País de 2002.

Desde el punto de vista de la función de los sitios web en general, parece evidente que están pensados con el objetivo de que los usuarios los visiten y naveguen por ellos fácilmente. Encontrar pronto y sin problemas la información que se busca, o realizar las gestiones para las que está pensado el sitio web deberían

Scire. $10: 2$ (jul.-dic. 2004) 123-136. 
ser los fines básicos de éste. Sin embargo, pese a lo obvio que ello pueda parecer, en muchas ocasiones, los diseñadores de sitios web tienen poco en cuenta al usuario. Buscan efectismos vacíos y espectacularidad, empleando para ello cuantos recursos técnicos están a su alcance. Así, más que facilitar la localización de información y la utilización de un sitio web la dificultan (Pearrow, 2000).

\section{Usabilidad}

Un factor clave para determinar la calidad de una web lo constituye el éxito o fracaso del usuario durante su exploración del sitio. Es lo que se denomina su experiencia de uso. La clave es determinar si quien navega por un sitio consigue entender o no su estructura y realizar con satisfacción aquello que pretendía realizar. Ante los millones de sitios web existentes en Internet, poner dificultades al usuario para navegar cómodamente en ellos significa invitarle a abandonar éste y a dirigirse a otro sitio en cuestión de segundos (Nielsen, 2000).

Los criterios que determinan el grado de usabilidad de un sitio web están impregnados de sentido común. Son normas básicas de diseño para que una página web pueda ser manejada adecuadamente, tales como usar fuentes de tipo y tamaño legible, buen contraste entre texto y fondo de página, uso de textos más cortos para la web que para los impresos, adecuada arquitectura de la información, descarga rápida de las páginas, etc. En cualquier caso, pequeñas mejoras en la usabilidad de diseño suelen contribuir a una importante mejora en el grado de éxito que consiguen los usuarios en la realización de las tareas previstas en un sitio web dado.

Tal vez la definición más clara, simple y eficaz del concepto de usabilidad es la que hace Nielsen (2003): "Usabilidad es un atributo de calidad que mide lo fáciles de usar que son las interfaces web". Sin embargo, las primeras definiciones de usabilidad no estaban ideadas para ser aplicadas al web, sino a el manejo de máquinas o dispositivos, en un primer momento, y de programas de ordenador, posteriormente. Así, de forma genérica, y sin pretender ser exhaustivos, podríamos clasificar las definiciones de usabilidad en varios grupos, dependiendo de su objeto de aplicación: a) productos genéricos, indeterminados, cosas y objetos, b) programas de ordenador, y c) sitios web.

Entre las que tienen un carácter genérico, al referirse a "cosas" o "productos" indeterminados, destacamos tres. Según Woodson es: "La práctica de diseñar productos de forma que los usuarios puedan realizar los requeridos uso, operación, servicio, y tareas de apoyo con el mínimo esfuerzo y el máximo de eficiencia" (Woodson, 1981). Para Shackel, "la usabilidad de un sistema o de un equipo, en los términos funcionales humanos, es la capacidad utilizar fácilmente y con eficacia por la gama especificada de usuarios, dados el entrenamiento y la

Scire. $10: 2$ (jul.-dic. 2004) 123-136. 
ayuda especificados, satisfacer la gama especificada de tareas, dentro de la gama especificada de guiones de entorno", o bien "la capacidad de ser utilizado por los seres humanos fácilmente y con eficacia" (Shackel 1991, p. 24, citado por Keinonen, 2003). Finalmente, para Pearrow: "Es el arte y ciencia de hacer una cosa más fácil de usar para el ser humano que la utiliza, al tiempo que se reduce la cantidad de tiempo y energía que conlleva usarlo" (Pearrow, 2002).

Relacionadas con tecnologías o programas informáticos, se presentan también tres definiciones. En primer lugar, para la norma ISO/IEC 9126: "La usabilidad se refiere a la capacidad de un software de ser comprendido, aprendido, usado y ser atractivo para el usuario, en condiciones específicas de uso". La norma ISO 9241 sobre requisitos ergonómicos para trabajo de oficina con pantallas, en su guía de usabilidad (apartado 11), define ésta como "la medida en la que un producto puede ser usado por usuarios específicos para conseguir objetivos específicos con efectividad, eficiencia y satisfacción en un contexto de uso determinado". Finalmente, según Hall (1997): "El término usabilidad es empleado para describir aquellos atributos de la tecnología que se considera que reflejan un buen diseño. La tecnología usable es fácil de usar, tolerante a los fallos del usuario, fácil de aprender a usar; y los usuarios se sienten satisfechos con su uso."

Entre las definiciones aplicables específicamente a sitios web, además de la citada de Nielsen, señalaremos la de Redish (2000). Para este autor, consiste en diseñar sitios web para que los usuarios sean capaces de "encontrar lo que necesitan, entender lo que encuentran y actuar apropiadamente... dentro del tiempo y esfuerzo que ellos consideran adecuado para esa tarea".

De forma general, la usabilidad se basa en cuatro principios:

- Respeto general a los estándares de la web: Los enlaces de color azul subrayado y los ya visitados de color morado; texto negro sobre fondo blanco; imágenes con texto alternativo; el usuario puede modificar el tamaño del texto en su navegador para leerlo mejor, etc.

- Ergonomía cognitiva y usos comunes en Internet: Acostumbramos a leer de izquierda a derecha y de arriba abajo; entendemos mejor las cosas si se las llama por su nombre más común; el logotipo suele estar arriba a la izquierda; la navegación se suele basar en colocar los ítems en un rail izquierdo, fichas superiores o categorías centrales; el buscador tiende a figurar arriba y a la derecha; la ayuda aparece arriba a la derecha, etc.

- Aspectos físicos de la legibilidad y percepción en una pantalla: En los textos largos, se leen mejor las fuentes sans-serif que las serif; el contraste entre texto y fondo influye en la legibilidad (negro sobre blanco, amarillo sobre negro...); los tipos de letra demasiado pequeños se ven y leen mal, etc.

Scire. $10: 2$ (jul.-dic. 2004) 123-136. 
- Rotulación y ayudas a la navegación: Dada la naturaleza hipertextual del web y, por tanto, la facilidad para pasar inmediatamente de un lugar a otro, se hacen necesarias determinadas ayudas a la navegación, que permitan ubicar al usuario dentro de la estructura de contenidos del web e identificar visualmente la permanencia o no dentro de la misma interfaz de trabajo.

En definitiva, la usabilidad se basa en no molestar ni hacer pensar en exceso al navegante (Krug, 2001) - hasta el más torpe debe ser capaz de navegar correctamente en la web - y en hacerle fácil y grata la experiencia en el sitio web. Para conseguirlo es preciso planificar desde el principio las acciones de desarrollo del sitio y orientarlas hacia ese fin. Es decir, el funcionamiento final de un sitio web tiene su germen en el proceso de diseño inicial, donde intervienen tanto elementos técnicos como de organización de contenidos (Rosenfeld, 1998).

\section{Metodología}

Hay diferentes maneras de estudiar y medir la usabilidad (Pearrow, 2000, p. 63), buena parte de ellas son complementarias entre sí. Las dos principales son el estudio heurístico, realizado por un grupo de expertos a través de un cuestionario de evaluación con una lista de criterios que chequear (Nielsen, 1994); y el test de usuarios, donde se registran los principales problemas que encuentran éstos cuando tratan de realizar las acciones concretas propuestas por el evaluador, así como los tiempos empleados en cada una de ellas (Krug, 2001, p. 139).

Para nuestro estudio hemos construido una heurística basada en la tabla de grados de recomendación de las cuestiones de usabilidad propuesta por Nielsen (Nielsen, 2002). Concretamente transformamos esta lista de cuestiones en una tabla de evaluación de la usabilidad. La tabla original de Nielsen constaba de tres columnas: en la primera se indicaba la cuestión de usabilidad a tratar; la segunda mostraba, de 1 a 3, el grado de recomendación de esa cuestión para el diseño de un sitio; y la tercera columna incluía una pequeña descripción de los aspectos a tener en cuenta en el diseño, lo que había que hacer y lo que no.

Nosotros introducimos dos nuevas columnas, hasta construir una tabla de cinco columnas. Una de ellas nos servía para que el evaluador indicara, de 0 a 3 , el grado de cumplimiento de esa cuestión en el web analizado. La última columna reflejaba el resultado de multiplicar el grado de recomendación que indicaba Nielsen, y que nosotros transformamos directamente en factor de ponderación, por el grado de cumplimiento observado por el evaluador.

Como no todas las cuestiones eran aplicables a todas las webs, no era posible realizar una comparación de varias webs a partir de la simple suma de valores ponderados. Si así se hiciera se tendería a asignar mayor puntuación a los sitios que incluyeran mayor cantidad de elementos - no todos necesarios en todas las

Scire. $10: 2$ (jul.-dic. 2004) 123-136. 
circunstancias - que a los que los tuvieran mejor implantados. Por esto, consideramos oportuno realizar una nueva ponderación de los resultados globales. Para ello, dividimos la cifra obtenida tras la suma (subtotal) de la puntuación obtenida para las cuestiones aplicables, y la cantidad resultante la transformamos a una escala de 0 a 10, para que así resultara más fácilmente observable y comparable. Además, realizamos una ampliación de la lista de cuestiones propuestas por Nielsen, incluyendo otras que él no había reflejado en su tabla, pero que consideramos importantes para ser medidas en esta heurística. Las nuevas cuestiones fueron la presencia de un título significativo en la página, la presencia o no de pop-ups, la inclusión de un eslogan adecuado, el etiquetado de imágenes y el uso o no menús desplegables.

Para determinar el ámbito de estudio del trabajo seleccionamos los diarios en línea relacionados con los principales diarios impresos de información general y de ámbito nacional (El País, El Mundo, ABC, La Razón). Junto a ellos, elegimos los quince diarios en línea de información general más visitados según la Oficina para la Justificación de la Difusión (OJD, 2003) y dos diarios electrónicos sin correlato impreso (Estrella Digital y Diario Directo).

De los diarios elegidos decidimos considerar como uno sólo todos los pertenecientes al grupo Vocento, puesto que el objeto de estudio era la interfaz de acceso a la información y ésta era idéntica en todos los diarios de este grupo, diferenciándose únicamente en los textos concretos de las noticias. Así, los diarios elegidos finalmente fueron $A B C$ (http://www.abc.es), Diario de Navarra (http://www.diariodenavarra.es), Diario Directo (http: //www.diariodirecto.com), El Confidencial (http://www.elconfidencial.com), El Mundo (http://www.elmundo.es), El País (http://www.elpais.es), El Periódico (http://www.elperiodico.es/), Estrella Digital (http://www.estrelladigital.es), Heraldo de Aragón (http://www.heraldo.es), La Nueva España (http:// www.elperiodico.es/), La Razón (http://www.larazon.es), La Vanguardia (http: //www.vanguardia.es), La Verdad (http://www.laverdad.es), La Voz de Galicia (http://www.lavozdegalicia.com/), Panorama Actual (http://www.panoramaactual.es), Vilaweb (http://www.vilaweb.com/). La recogida de datos para la evaluación de las páginas de inicio de estos diarios se realizó durante el mes de octubre de 2003. A los datos recogidos se les aplicaron los factores de ponderación anteriormente referidos, para poder compararlos fácilmente y representarlos gráficamente.

\section{Resultados}

Tras la tabulación de los datos obtuvimos una tabla de grados de usabilidad de las páginas de inicio de diarios en línea que, en una escala de 0 a 10, ofrecía los valores reflejados en la tabla II.

Scire. $10: 2$ (jul.-dic. 2004) 123-136. 


\section{Juan Carlos García Gómez}

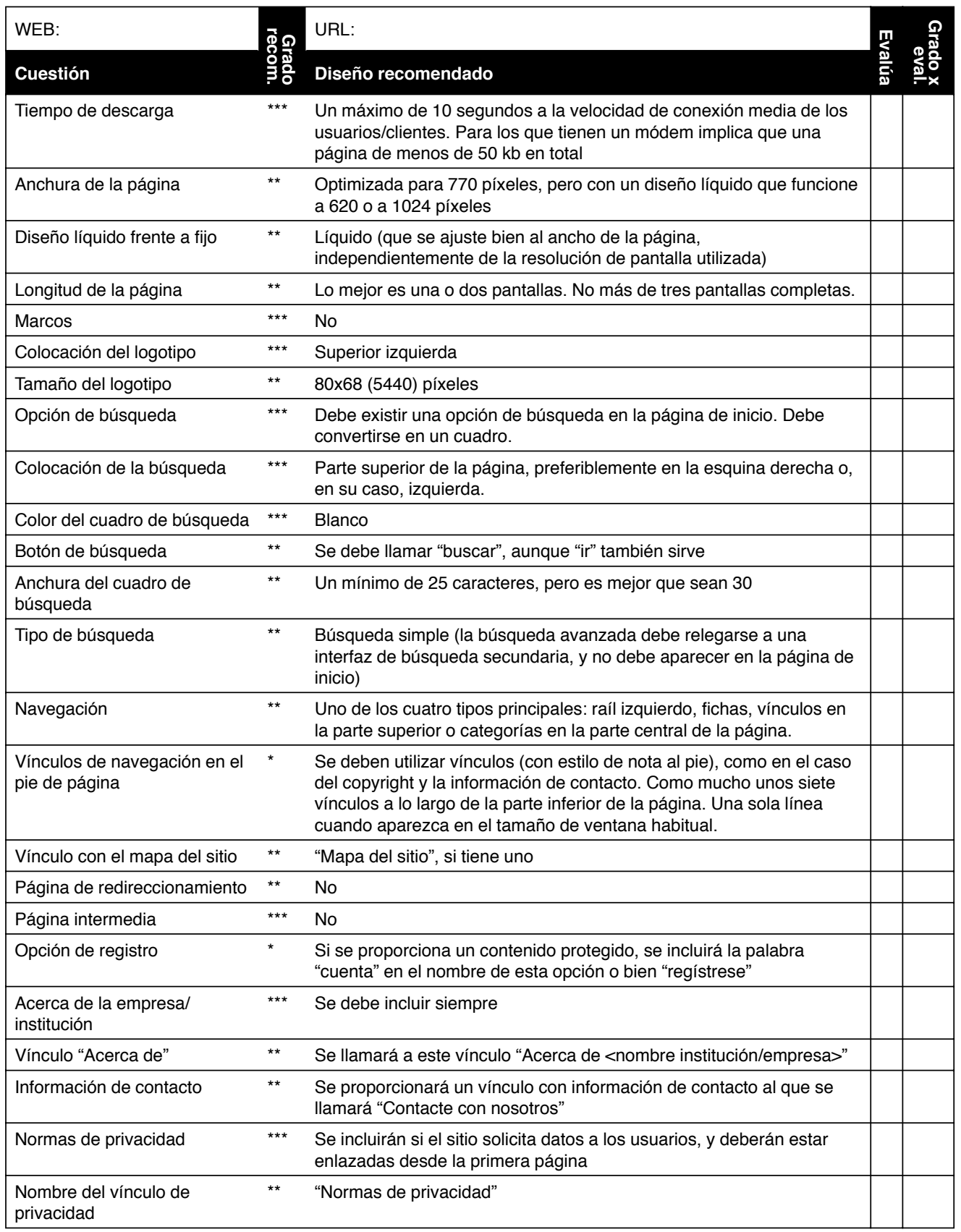

Scire. $10: 2$ (jul.-dic. 2004) 123-136. 


\begin{tabular}{|c|c|c|c|c|}
\hline Ofertas de empleo & ** & $\begin{array}{l}\text { Se debe incluir un vínculo explícito en la página de inicio si la oferta } \\
\text { de empleo es importante para la empresa/institución (de otro modo, } \\
\text { se enumerará los empleos en "Acerca de la empresa"). El vínculo se } \\
\text { debe llamar "Ofertas de empleo" }\end{array}$ & & \\
\hline Ayuda & * & No se ofrecerá a menos que la complejidad del sitio la haga inevitable & & \\
\hline Colocación de la ayuda & ** & Superior derecha & & \\
\hline $\begin{array}{l}\text { Música con reproducción } \\
\text { automática }\end{array}$ & *** & No & & \\
\hline Animación & ** & No & & \\
\hline Imágenes/llustraciones & * & Entre el 5 y el $15 \%$ del espacio de la página de inicio & & \\
\hline Publicidad & ** & Como mucho, 3 anuncios (externos o internos) & & \\
\hline Color del cuerpo de texto & ** & Negro & & \\
\hline Tamaño del cuerpo de texto & * & 12 puntos & & \\
\hline $\begin{array}{l}\text { Tamaño del cuerpo de texto } \\
\text { fijo }\end{array}$ & $* \star *$ & $\begin{array}{l}\text { No. Se utilizarán siempre tamaños relativos que posibiliten a los } \\
\text { usuarios hacer que el texto tenga el tamaño deseado }\end{array}$ & & \\
\hline $\begin{array}{l}\text { Tipo de fuente del cuerpo } \\
\text { de texto }\end{array}$ & * & Sans-Serif & & \\
\hline Color de fondo & ** & Blanco & & \\
\hline $\begin{array}{l}\text { Color de los vínculos no } \\
\text { visitados }\end{array}$ & ** & Azul & & \\
\hline $\begin{array}{l}\text { Color de los vínculos } \\
\text { visitados }\end{array}$ & * & Morado & & \\
\hline $\begin{array}{l}\text { Colores distintos para los } \\
\text { vínculos visitados y los no } \\
\text { visitados }\end{array}$ & $* \star \star \star$ & $\begin{array}{l}\text { Sí. Los vínculos no visitados deben llevar colores saturados. Los } \\
\text { vínculos visitados deben llevar un color poco saturado o menos } \\
\text { prominente, pero no el gris claro. }\end{array}$ & & \\
\hline Subrayado del vínculo & ** & Sí, excepto posiblemente en las listas de las barras de navegación & & \\
\hline Título (<Title>) & 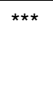 & $\begin{array}{l}\text { Debe empezar por una palabra que transmita información (nombre } \\
\text { de la empresa) y llevar una breve descripción. No poner el dominio o } \\
\text { "home". 7-8 palabras. }\end{array}$ & & \\
\hline Pop-Ups & *** & No & & \\
\hline Eslogan & *** & $\begin{array}{l}\text { Incluir al inicio un eslogan claro que indique la actividad y ventajas de } \\
\text { la página. Si no se incluye, la página debe dejar suficientemente clara } \\
\text { la actividad a la que se dedica }\end{array}$ & & \\
\hline Imágenes Etiquetadas & ** & $\begin{array}{l}\text { Sí. Especialmente ilustraciones y fotografías, deben llevar un texto } \\
\text { alternativo que se muestre cuando se pasa el ratón por encima. Usar } \\
\text { validadores (www.tawdis.net) }\end{array}$ & & \\
\hline Menús Desplegables & ** & $\begin{array}{l}\text { No. Especialmente si esos vínculos son importantes para la } \\
\text { navegación. Mejor listados en la página. }\end{array}$ & & \\
\hline \multicolumn{5}{|c|}{ Subtotal: } \\
\hline \multicolumn{5}{|c|}{ Subtotal Ponderado $=$ Subtotal $/ \mathrm{N}^{\circ}$ Ítems aplicables } \\
\hline & & Total $\left(\right.$ de 0 a 10) $=\left(\text { Subtotal } / \text { Media máx. }\left(6^{\prime} 4\right)\right)^{\star}$ & *10 & \\
\hline
\end{tabular}

Scire. $10: 2$ (jul.-dic. 2004) 123-136. 


\begin{tabular}{|l|r|}
\hline Diario en línea & Puntuación \\
\hline Vilaweb & 7,09 \\
\hline Diario Directo & 6,90 \\
\hline La Razón & 6,69 \\
\hline El País & 6,57 \\
\hline El Mundo & 6,39 \\
\hline Panorama Actual & 6,37 \\
\hline ABC & 6,12 \\
\hline La Nueva España & 6,08 \\
\hline Heraldo de Aragón & 5,96 \\
\hline La Vanguardia & 5,91 \\
\hline La Voz de Galicia & 5,77 \\
\hline La Verdad / Vocento & 5,70 \\
\hline El Confidencial & 5,48 \\
\hline El Periódico & 5,41 \\
\hline Estrella Digital & 5,30 \\
\hline Diario de Navarra & 4,50 \\
\hline
\end{tabular}

Tabla II. Valores de usabilidad

A tenor de los datos obtenidos de la evaluación de las páginas estudiadas, las dos más usables resultaron ser las de Vilaweb (figura 1) y Diario Directo (figura 2). En ambos casos se trata de diarios en línea sin correspondencia o relación directa con un diario impreso. Las siguientes en aparecer en dicha lista son las ediciones en línea de los diarios nacionales impresos de mayor difusión (La Razón, El País, El Mundo, ABC), entre las que se sitúa otro diario en línea (Panorama Actual). Las menos usables fueron las del Diario de Navarra (figura 3) y Estrella Digital (figura 4). En esta tabla, las que menor grado de usabilidad presentan son las ediciones en línea de diarios regionales impresos y el resto de diarios en línea. En una escala de 0 a 10 los resultados oscilaron entre 4,5 (Diario de Navarra) y 7,09 (Vilaweb). Las versiones en línea de los diarios nacionales impresos presentaron muy poca diferencia entre sí (poco más de medio punto), oscilando entre 6,12 (ABC) y 6,69 (La Razón). La media aritmética de los valores de todas las web analizadas fue 6,01. De estos valores se desprende que, aunque no hay webs que presenten graves deficiencias generales, ninguno de los analizados presenta un resultado plenamente satisfactorio.

Otra cuestión que pudimos constatar es que las webs que reciben un alto número de visitas tienden a atraer mucha publicidad, lo que se traduce en la pre- 
sencia de banners y pop-ups, elementos que dificultan la facilidad de uso de la página, lo que termina por rebajar notablemente su valoración.

También resultaba destacable observar cómo, pese a que las recomendaciones respecto del tamaño de la página principal indican que, para una descarga lo suficientemente ágil, el tamaño máximo recomendable para una página de inicio es de 50 kb (Nielsen, 2002; King, 2003), la mayoría de los diarios en línea analizados contenían páginas de tamaño superior a las $200 \mathrm{~kb}$, con una media de 253 kb. Sólo La Voz de Galicia (160 kb) y Villaweb (173) no llegaban a rebasar los $200 \mathrm{~kb}$, y, aún así, triplicaban el tamaño recomendable (50 kb). No obstante, este exceso de tamaño no se suele emplear en material gráfico informativo

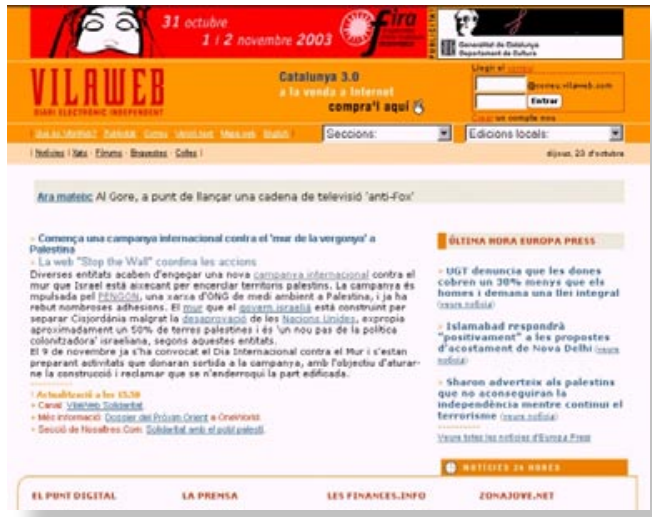

Figura 1. Página de inicio de Vilaweb

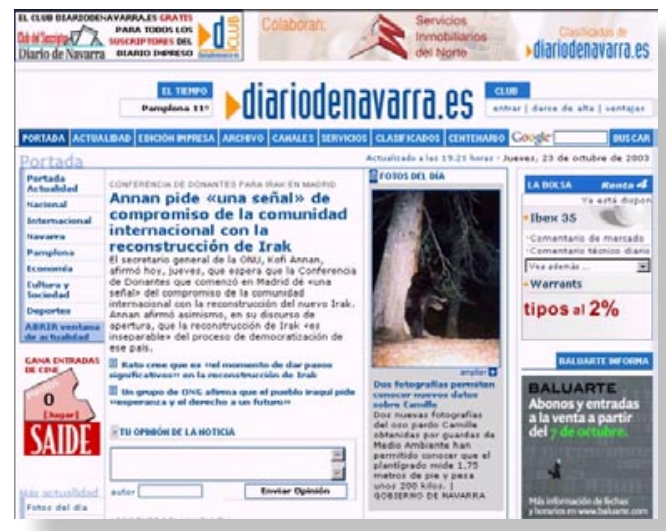

Figura 3. Página de inicio del Diario de Navarra

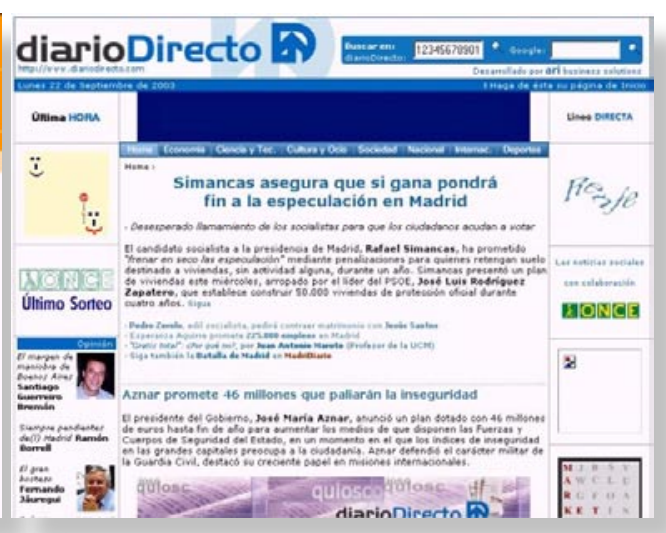

Figura 2. Página de inicio de Diario Directo

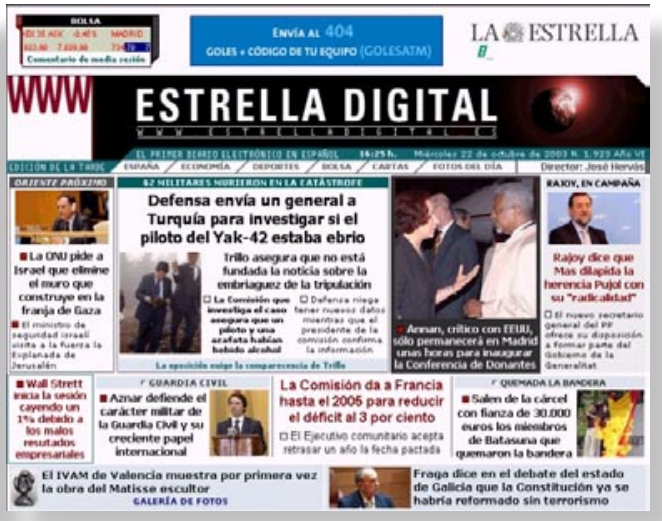

Figura 4. Página de inicio de Estrella Digital

Scire. $10: 2$ (jul.-dic. 2004) 123-136. 
(fotografías e infografías), sino más bien en material gráfico publicitario propio o ajeno (banners), iconografía para organización de contenidos en la página y código fuente para la definición de formatos de diseño especiales, tales como la detección y asignación de variables de presentación de la información - para optimizarla según los distintos navegadores - o la inserción de elementos dinámicos. Relacionado con este aspecto cabe citar también la tendencia a abusar de elementos gráficos en estas páginas de inicio. En casi todos los casos se superan los límites recomendables de proporción gráfico/texto, superándose casi sistemáticamente el 15\% aconsejable (Nielsen, 2002).

Ninguna de las páginas de inicio estudiadas empleaba diseño líquido. Es decir, en todos los casos éstas contaban con un ancho fijo en su página - siempre de 800 píxeles - , en lugar de definir éste mediante porcentajes. Definir el ancho de página en porcentaje, en lugar de un ancho fijo en píxeles, permitiría aprovechar mejor la superficie de pantalla disponible, en los casos de pantallas grandes, y evitar que sea necesario usar la barra de desplazamiento lateral para ver los contenidos de la zona derecha de la pantalla, en el caso de monitores pequeños o configurados a baja resolución.

\section{Conclusiones}

Las páginas de inicio de los diarios en línea tienden a ser tanto más usables cuanto más sencillo sea su diseño. El minimalismo de éste tiende a orientar al usuario a lo esencial (los contenidos), evitando distraerle con elementos secundarios o provocarle retrasos en el acceso a la información. Por el contrario, el exceso de sofisticación en el diseño de una web en busca de la originalidad tiende a la construcción de sitios web en los que no se respetan los estándares y los usos más frecuentes en Internet, lo que termina por hacer ese sitio menos usable. Tal vez, disponer de un elevado presupuesto para abordar un proyecto web pueda crear cierta propensión, dentro del equipo de desarrollo, a emplear abundantes efectismos e incorporar los últimos avances tecnológicos. Con ellos se buscaría una sofisticación tecnológica y visual que ayudara a justificar ante un equipo de directivos, no siempre con la adecuada formación en este terreno, el empleo de un presupuesto elevado. Esto, por tanto, explicaría que los mejores resultados obtenidos correspondan a las páginas de inicio de webs de grupos empresariales con presupuesto medio-bajo, en los que se optó por un diseño sin exceso de sofisticación.

En general, la metodología empleada mejora algunos de los sistemas de observación y evaluación de sitios web. No obstante, sigue incorporando un alto componente interpretativo, al supeditar la medición del grado de cumplimiento de las cuestiones a la observación y valoración humanas. Por otra parte, el sistema de ponderación empleado en nuestra metodología tiende a premiar a las web sin

Scire. $10: 2$ (jul.-dic. 2004) 123-136. 
buscador frente a las que tienen uno de calidad media. En la tabla se evaluaban un gran número de cuestiones relativas al buscador. De este modo, las páginas sin buscador obtenían una penalización en sólo una de las cuestiones (presencia o no de buscador), pero, por el contrario, no se les evaluaría, ni positiva ni negativamente, el resto de las relacionadas con este aspecto. Así, sería recomendable una revisión de la metodología que compensara esta disfunción.

Tras el análisis realizado con esta muestra, se pueden detectar ciertas tendencias generales en relación al diseño de las webs de diarios en línea. En primer lugar, todos los webs estudiados tienen un tamaño excesivo - en torno a 250 $\mathrm{kb}-$, lo que implica un tiempo de descarga excesivamente lento para terminales equipados con conexiones a la red lentas. En segundo lugar, no se suelen emplear los estándares web para los links, aunque normalmente éstos se distinguen perfectamente gracias al color y tipografía utilizados. En tercer lugar, las webs de diarios en línea pertenecientes a grupos empresariales medio-bajos tienden a no ofrecer buscador. En cuarto lugar, el ancho de página siempre está optimizado a 800x600 (ancho fijo), en formato de cuatro columnas. La primera de ellas se reserva a la navegación principal, las dos centrales contienen las noticias y la cuarta alberga la navegación secundaria y el acceso a servicios de valor añadido. En quinto lugar, los resultados muy bajos tienden a deberse en su mayoría a deficiencias en los sistemas de ayuda a la navegación, rotulación e información de contacto.

Finalmente, la principal conclusión que nos brindan los resultados del estudio es que, independientemente del presupuesto o medios técnicos disponibles, la simplificación del diseño de la página de inicio de un diario en línea es la mejor manera de que los usuarios accedan sin problemas a los contenidos del diario.

\section{Referencias}

Agosti, Mristella; Crivellari, Franco; Melucci, Massimo (1999). The effectiveness of metadata and other content descriptive data in web information retrieval. URL: <http: //dei.unipd.it>. Consultado: 2003-12-07.

Arbildi, Iñigo; Serrano, Jorge (2002). Usabilidad ElPais.es. // URL: <http://trucosdegoog le.blogspot.com >. Consultado: 2004-01-07.

Donaghy, Roger (2002). Evaluating online newspapers using established web design guidelines. // School of Information and Library Science. University of North Carolina, 2002. URL: <http://neoref.ils.unc.edu/2776.pdf>. Consultado: 2004-01-07

Hall, Roger (1997). Ergonomics, Design and New Technology. // The 1997 ESA Ron Cumming Memorial Lecture. URL: <http://www.whs.qld.gov.au/conference/ ergonomic97/hall2.pdf $>$. Consultado: 2004-1-2.

International standards for HCI and usability. // UsabilityNet. URL: <http:// www.hostserver150.com/usabilit/tools/r_international.htm\#9241-11>. Consultado: 2003-12-30.

Scire. $10: 2$ (jul.-dic. 2004) 123-136. 
Keinonen, Turkka (1998). One-dimensional usability - influence of usability on consumers' product preference. Trad. Routio Penti. // A21 de la UIAH. Helsinki. URL: < http://www2.uiah.fi/projects/metodi/258.htm >. Consultado: 2003-2-1.

King, Andrew B. (2003). Speed Up Your Site: Web Site Optimization. Indianapolis: New Riders, 2003.

Krug, Steve (2001). No me hagas pensar: una aproximación a la usabilidad en la Web. Madrid: Prentice-Hall, 2001.

Martínez Méndez, F. J. (2002). Propuesta y desarrollo de un modelo para la evaluación de la recuperación de información en Internet· Tesis Doctoral_[En línea]Alicante; Biblioteca Cervantes, 2002. URL: \http://cervantesvirtual.com/FichaObra.html?Re $\mathrm{f}=10010$. Consultado: 10 de noviembre de 2003 .

Nielsen, Jakob (1994). How to conduct a heuristic evaluation. // Heuristic Evaluation. URL: <http://www.useit.com/papers/heuristic/heuristic_evaluation.html>. Consultado: 2003-12-07.

Nielsen, Jakob (2000). Usabilidad: Diseño de sitios web. Madrid: Prentice Hall, 2000.

Nielsen, Jakob (2003). Usability 101. // Alertbox, August 25 (2003). URL: <http:// useit.com/alertbox/20030825.html>. Consultado: 2003-08-26.

Nielsen, Jakob; Tahir, M. (2002). Usabilidad de páginas de inicio: Análisis de 50 sitios web. Madrid: Prentice Hall, 2002.

Oficina de Justificación de la Difusión. (2003). Medios electrónicos controlados. // URL: <http://www.ojd.es/f_medios_electronicos.htm>. Consultado: 2003-12-07.

Pearrow, M. (2000). Manual de usabilidad de sitios web. Rockland, MA: Charles River Med, 2000.

Pearrow,M.(2002). UsabilityFAQ.//usablesites.com. URL:<http://www.usablesites.com/ faq.html>. Consultado: 2003-12-30.

Redish, Janice; Dumas, J. (1999). A Practical Guide to Usability Testing. Intellect, 1999.

Sánchez de Ocaña, J. María (2002). Análisis de usabilidad del nuevo Home Page de El País. // Evolucy. Barcelona. (2002). <http://www.evolucy.com/esp/columns/ 20021129_el_pais.html>. Consultado: 2004-01-07.

Rosenfeld, Louis; Morville, Peter (2000). Arquitectura de la información para la World Wide Web. Cambridge (etc.): O'Reillly, 2000.

Woodson, W. E. (1981). Human factors design handbook. New York: McGraw-Hill, 1981. 